\title{
Avaliação das Propriedades Mecânicas de Espumas Híbridas de Vidro Bioativo/Álcool Polivinílico para Aplicação em Engenharia de Tecidos
}

Agda Aline Rocha de Oliveira, Juliano Elvis de Oliveira, Rodrigo Lambert Oréfice, Herman Sander Mansur, Marivalda de Magalhães Pereira

Departamento de Engenharia Metalúrgica e de Materiais - Universidade Federal de Minas Gerais Rua Espírito Santo, n35, Centro, Belo Horizonte, MG. CEP: 31160-030

e-mail: agdalinero@yahoo.com, julianoufmg@yahoo.com.br, rorefice@demet.ufmg.br, hmansur@demet.ufmg.br, mpereira@demet.ufmg.br

\section{RESUMO}

Híbridos de vidro bioativo/polímero são materiais de grande interesse em aplicações biomédicas devido às suas propriedades, que combinam a bioatividade dos materiais cerâmicos, com a flexibilidade dos polímeros. Para regeneração do tecido ósseo, propriedades mecânicas da matriz são críticas e o módulo e a resistência mecânica do material devem ser similares aos do osso natural. Em trabalhos anteriores desenvolvidos no grupo obtiveram-se espumas híbridas $80 \%$ vidro bioativo/20\% álcool polivinílico (PVA), para aplicação em engenharia de tecidos. Neste trabalho foi aumentado o teor de PVA dos híbridos para otimizar suas propriedades mecânicas. Os híbridos foram preparados com fase inorgânica $70 \% \mathrm{SiO}_{2}-30 \% \mathrm{CaO}$ e teores de PVA de 20 a $60 \%$, através da hidrólise ácida de tetraetil ortosilicato, adição de $\mathrm{CaCl}_{2}, \mathrm{PVA}$, surfactante e HF. A secagem das espumas mostrou-se crítica, ocorrendo grande contração do gel As amostras foram secas por duas rotas: (1): pré-secagem a $40^{\circ} \mathrm{C}$ em estufa e secagem a vácuo; (2): pré-secagem a $40^{\circ} \mathrm{C}$ em estufa com circulação de ar e secagem a alto vácuo. A rota de secagem 2 apresentou maior perda de água e menor contração das amostras. Corpos de prova cúbicos, 10x10x10mm, foram submetidos a ensaios de compressão com velocidade de aplicação de carga de $0,5 \mathrm{~mm} / \mathrm{min}$. Observou-se que o aumento do teor de polímero na composição das espumas melhorou suas propriedades mecânicas.

Palavras chaves: Híbridos, vidro bioativo, polímero, matrizes, secagem, compressão.

\section{Mechanical Behavior of Bioactive Glass/Polyvinyl Alcohol Hybrid Foams for Bone Tissue Engineering}

\section{ABSTRACT}

Bioactive glass/ polymer hybrids are materials of high interest for biomedicals applications because their assets, they combine the bioactivity of ceramics, with the flexibility of the polymers. In bone regenerations, mechanicals properties of the scaffold are criticisms and they must be similar to the bone properties. In previous works, hybrid foams with $80 \%$ bioactive glass and $20 \%$ polyvinyl alcohol (PVA) were prepared by sol-gel process to application as scaffold for bone tissue engineering. In this work, the PVA fraction of the hybrids was increase for to improve their mechanicals properties. The hybrids were prepared with composition inorganic of $70 \% \mathrm{SiO} 2-30 \% \mathrm{CaO}$ and PVA fractions of 20 to $60 \%$ by sol-gel method. The drying of the foams was a criticism stage, occurring ample contraction from the gel. The samples were drying for two routes: (1) pre-drying at $40^{\circ} \mathrm{C}$ for 7 days and drying at vacuum for 48 hours; (2) pre-drying with air circulation at $40^{\circ} \mathrm{C}$ for 7 days and drying at high vacuum for 48 hours. The drying route 2 had the most lost of water and the least contraction of samples. Five specimens of hybrids samples with dimensions 10x10x10mm were compressed at $0,5 \mathrm{~mm} / \mathrm{min}-1$. The increase of PVA fraction in the hybrids improves their mechanicals properties.

Keywords: Hybrids, bioactive glass, polymer, scaffolds, drying, compression.

\section{INTRODUÇÃO}

Quando uma perda significativa de tecido ocorre como resultado de trauma ou da extirpação de tecido doente ou canceroso, a cura total ocorre apenas com a ajuda de enxertos implantados. Terapias 
empregando material de enxerto retirado de um sítio diferente num paciente (autoenxerto), de outro doador humano (homoenxerto) ou de outra espécie viva ou não-viva (hetero ou xenoenxerto) têm sido restringidas devido à disponibilidade limitada de material, às complicações cirúrgicas e de múltiplos estágios em prejuízo do sítio de colheita, e ao risco de transmissão de doenças. Estes fatores criam uma grande demanda para substitutos sintéticos especialmente projetados e manufaturados para agir como matrizes para engenharia de tecidos [6]. A engenharia de tecidos compõe uma área de pesquisa de grande importância que consiste na utilização de biomateriais como matrizes para dar suporte a culturas de células de maneira a desenvolver tecidos vivos. Um biomaterial provê as bases para o tecido em crescimento, promovendo o reparo, a proliferação e a regeneração do tecido natural, reconstruindo e substituindo tecidos danificados. Assim, tecidos podem ser reparados a partir de culturas realizadas das próprias células do paciente, eventualmente sem deixar resíduos do material artificial pela utilização de materiais biodegradáveis. Desta maneira, respostas celulares que normalmente só ocorrem naturalmente, podem ser induzidas, acelerando os processos de cura e/ou reabilitação (Langer, 2004).

Dentre os inúmeros requisitos que devem ser satisfeitos para que os materiais sejam aplicados como matrizes na engenharia de tecidos incluem-se: (i) estrutura tridimensional com alta porosidade de macroporos (diâmetros da ordem de $100 \mu \mathrm{m}$ ) interconectados para que haja migração celular e nutrição em todo o material; (ii) composições biodegradáveis ou reabsorvíveis, com taxas de degradação e reabsorção controladas compatíveis com o crescimento da célula/tecido in vitro ou in vivo, (iii) superfície bioativa para promover adesão, proliferação e diferenciação celular; (iv) propriedades mecânicas adequadas às condições físiológicas e ao tecido substituído, assim como os tecidos vizinhos; (iv) boa distribuição espacial e uniformidade de estrutura para promover ancoramento homogêneo de células e; (v) ser facilmente processado em grande variedade de formas e tamanhos (Buckley, 2004). Em particular, para a substituição de tecido ósseo, além de todas as características já citadas, é desejável que a matriz possua comportamento mecânico compatível ao osso, com módulo de elasticidade de 300-500 MPa e deformação elástica de 5-10\%. Essas propriedades devem ser mantidas à medida que ocorre a degradação da matriz e o crescimento do novo tecido [9].

Vidros bioativos possuem boa aplicação como matrizes para engenharia de tecido ósseo. Quando implantados no corpo suscitam uma resposta bioativa na interface do material [5]. Além disso, os produtos de dissolução dos vidros bioativos exercem controle genético sobre fatores de crescimento ósseo [ㅁ]. Assim, trabalhos anteriores focaram no desenvolvimento de processos que permitissem a obtenção de vidros bioativos porosos a partir do processo sol-gel [4]. Essas estruturas possuíam porosidade e interconectividade de poros adequadas, mas apresentaram resistência mecânica e tenacidade baixas, o que limitava a sua aplicação em engenharia de tecidos.

Uma abordagem para melhorar as propriedades mecânicas dos vidros bioativos é a produção de híbridos orgânico-inorgânicos, na qual uma fase inorgânica, com dimensões nanométricas, é inserida na matriz polimérica flexível. A união de polímeros com matrizes cerâmicas permite a produção de novos materiais com as propriedades superiores. A lei de misturas proposta por Reuss afirma que as propriedades do material híbrido estão relacionadas à fração volumétrica de seus constituintes [7], assim, pode-se combinar a bioatividade dos materiais cerâmicos, com a flexibilidade dos compostos e polímeros orgânicos [13]. O processo sol-gel apresenta-se potencialmente útil em possibilitar tal combinação em escalas moleculares e nanométricas. Isso por que permite a preparação de materiais cerâmicos em temperaturas compatíveis com o processamento de polímeros [12].

O processo se inicia com a mistura de água, catalisador e o alcóxido metálico. Com o contato das moléculas de água com as de alcóxidos, iniciam-se as reações de hidrólise e condensação. De acordo com o produto final desejado, algumas condições devem ser obedecidas para garantir o sucesso na obtenção dos diferentes materiais tais como monolitos, fibras e filmes finos. O sol obtido é vazado em um molde de geometria desejada. A forma final do gel é uma reprodução do molde utilizado, embora as dimensões do produto final fiquem alteradas devido às contrações que ocorrem durante o processo. A gelificação envolve o crescimento e agrupamento de unidades poliméricas para formar uma rede contínua que se estende através do líquido. Quando os polímeros em solução crescem através das reações de condensação, eles se unem para formar macromoléculas que se estenderão por toda a solução. Esse ponto representa a transição de sol para gel. O processo de mudança na estrutura e propriedade do gel que ocorre após a gelificação é conhecido como envelhecimento. As reações químicas que causam a gelificação continuam a ocorrer mesmo após o ponto gel ser estabelecido, produzindo resistência, dureza e contração na rede. Durante o envelhecimento ocorrem mudanças em muitas propriedades estruturais do gel, tais como tamanho médio de poros, porosidade e área superficial. Na secagem ocorre a remoção do líquido contido nos poros interconectados do gel. A estrutura porosa de um gel produzido pela secagem de um sistema de duas fases sólido-líquido, é grandemente influenciada pela estrutura inicial da rede sólida e pela interação entre as fases sólida e líquida. Durante a secagem por aquecimento ocorre (i) a diminuição do volume do gel, igual ao volume de líquido perdido por evaporação; (ii) quando o gel é resistente o suficiente para suportar a compressão, o menisco é 
deslocado para baixo da superfície e os poros começam a esvaziar; (iii) remoção do líquido restante dentro dos poros por difusão de seu vapor até a superfície; resultando em um xerogel [1].

Espumas híbridas de vidro bioativo/álcool polivinílico (PVA) foram obtidas pelo método sol-gel com resultados promissores $[10,11]$, uma vez que a presença do polímero aumenta a tenacidade em comparação com as espumas de vidro bioativo. As espumas foram obtidas com teor de polímeros de $20 \%$. O PVA é uma escolha adequada por se solubilizar facilmente em água e é, geralmente, considerado não tóxico.

No presente trabalho foram obtidas espumas híbridas de vidro bioativo/PVA pelo método sol-gel com teores de polímeros entre 20 e $60 \%$ e composição $70 \% \mathrm{SiO} 2 / 30 \% \mathrm{CaO}$ da fase inorgânica. O aumento do teor de polímero na composição do material visava melhorar suas propriedades mecânicas, para aproximalas às do osso humano, mantendo sua porosidade e seu caráter bioativo. As amostras eram secas à baixa temperatura, uma vez o tratamento a altas temperaturas levaria à decomposição do polímero. A secagem dos híbridos obtidos mostrou-se uma etapa crítica do processo, na qual ocorria grande contração do gel, reduzindo substancialmente o tamanho de poros das amostras e levando à formação de trincas durante o tratamento térmico. Outra dificuldade encontrada foi quando se fez necessário obter amostras totalmente secas para sua caracterização. As espumas foram então submetidas à duas rotas de secagem para se determinar qual seria a adotada como procedimento de secagem.

O objetivo deste trabalho é avaliar as propriedades mecânicas e a porosidade das espumas híbridas de vidro bioativo/PVA com diferentes composições do polímero. As propriedades mecânicas compreendem a resposta dos materiais às influências mecânicas externas, manifestadas pela capacidade de desenvolverem deformações reversíveis e irreversíveis, e resistirem à fratura. Essas características dos materiais são geralmente avaliadas por meio de ensaios, que indicam dependências tensão-deformação [2] ]. A presença de poros faz com que as cerâmicas apresentem baixa resistência a tração, pois as tensões têm o efeito de propagar as trincas existentes. Por outro lado quando o material é submetido a cargas de compressão sua resistência mecânica aumenta significativamente [14]. Durante o ensaio de compressão os poros tendem a ser fechados. Esse efeito está representado na Figura 1 []․

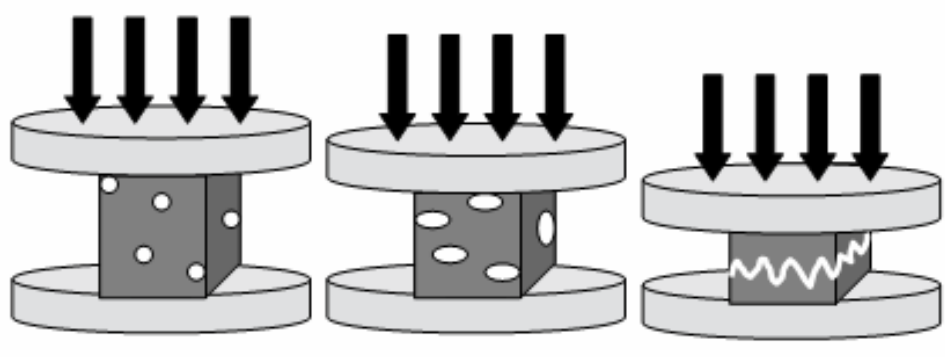

Figura 1: Esquema do efeito de poros durante o ensaio de compressão.

\section{MATERIAIS E MÉTODOS}

Híbridos do sistema vidro bioativo/PVA foram preparados com teores de polímero de 20 a $60 \%$. As espumas foram obtidas a partir de uma solução sol-gel precursora através da hidrólise ácida de tetraetil ortosilicato (TEOS) e subseqüente adição de cloreto de cálcio $\left(\mathrm{CaCl}_{2} \cdot 2 \mathrm{H}_{2} \mathrm{O}\right)$, adicionados em quantidades adequadas para obter-se a composição da fase vítrea de $70 \% \mathrm{SiO}_{2}-30 \% \mathrm{CaO}$. A razão molar água deionizada/TEOS usada foi igual a 12. Uma solução $20 \%$ em massa de PVA, em quantidade variável dependendo do teor de polímero desejado no hibrido, o surfactante lauril éter sulfato de sódio (LESS) e solução de ácido fluorídrico $0,05 \mathrm{~mol} / \mathrm{L}$ (catalisador da gelificação) foram adicionados ao sol. Para cada batelada de $40 \mathrm{~mL}$ de sol, foram adicionados 1,5 mL de LESS e $6 \mathrm{~mL}$ da solução de HF. A mistura foi então agitada vigorosamente para formação da espuma, que foi vertida em recipientes onde ocorreu a gelificação. As amostras foram então envelhecidas por 72 horas e depois secas à baixa temperatura, por duas rotas distintas. A rota 1 consistia na pré-secagem por aquecimento a $40^{\circ} \mathrm{C}$ em estufa por 1 semana, seguida da secagem a vácuo por 48 horas. E a rota 2 , pré-secagem por aquecimento a $40^{\circ} \mathrm{C}$ em estufa com circulação de ar por 1 semana e secagem a alto vácuo por 48 horas. Foram avaliadas a perda de água em função do tempo de secagem, a contração das amostras e a estrutura de poros resultante para as duas rotas utilizadas.

A caracterização dos poros das espumas obtidas foi feita por MEV e a avaliação das suas propriedades mecânicas por ensaios de compressão. Os ensaios de compressão foram realizados em corpos de prova cúbicos das espumas híbridas, com dimensões 10x10x10mm, em máquina universal de ensaios mecânicos Emic DL3000, com velocidade de aplicação de carga de $0,5 \mathrm{~mm} \cdot \mathrm{min}^{-1}$. Por não haver norma específica para este tipo de material (híbridos macroporosos) foram utilizados parâmetros comumente adotados para ensaios de compressão em cerâmicas. Foram usados cinco corpos de prova (cp) para cada 
composição do híbrido. As superfícies das placas fixa e móvel do equipamento foram envolvidas com filme plástico para diminuir o efeito do atrito entre as placas e as superfícies do material.

\section{RESULTADOS}

Foi possível obter espumas híbridas de vidro bioativo/PVA com teores de polímero de $20 \%$ a $60 \%$ em massa. A partir de $70 \%$ de polímero, não ocorreu a gelificação do sol, inviabilizando a produção de híbridos com composições iguais e acima desse teor. A terminologia adotada para identificar as amostras, assim como suas composições, estão representadas na Tabela 1.

Tabela 1: Composição inicial, em massa, dos híbridos e terminologia das amostras

\begin{tabular}{lll}
\hline Amostras & $\% \mathrm{~m} / \mathrm{m}$ Vidro bioativo & $\% \mathrm{~m}$ PVA \\
\hline 7S* & 100 & 0 \\
7S/2PVA & 80 & 20 \\
7S/3PVA & 70 & 30 \\
7S/4PVA & 60 & 40 \\
7S/5PVA & 50 & 50 \\
7S/6PVA & 40 & 60 \\
\hline *composição da fase inorgânica $70 \% \mathrm{SiO}_{2}-30 \% \mathrm{CaO}$
\end{tabular}

\subsection{Rotas de Secagem}

As rotas de secagem 1 e 2 foram avaliadas quanto à contração sofrida pelas amostras e os resultados são apresentados na Tabela 2. Pode-se observar que as espumas submetidas à secagem pela rota 1 apresentaram maiores contrações dos seus diâmetros, variando de 39,5, amostras 7S/2PVA, a 43,7\%, amostras 7S/6PVA. Por outro lado, as amostras secas pela rota 2 tiveram contrações variando de 30,1 (7S/2PVA) a $35,4 \%(7 \mathrm{~S} / 6 \mathrm{PVA})$.

Tabela 2: Porcentagem de contração do diâmetro das amostras após secagem.

\begin{tabular}{llllll}
\hline \%PVA & 20 & 30 & 40 & 50 & 60 \\
\hline Rota 1 & 39,5 & 40,8 & 41,7 & 42,8 & 43,7 \\
Rota 2 & 30,1 & 32,4 & 33,5 & 34,2 & 35,4 \\
\hline
\end{tabular}

Os teores de perda de água em função do tempo de secagem foram avaliados para as rotas 1 e 2 e os resultados estão representados nas Figuras 2 e 3, respectivamente. As espumas submetidas à rota 1 tiveram perda de água de 25 (7S/2PVA) a 70\% em massa (7S/APVA) em 9 dias. Já nas amostras secas pela rota 2, as perdas de água variaram de 68 (7S/2PVA) a 92 (7S/6PVA) no mesmo período. Determinou-se, pelos resultados obtidos das curvas de secagem, que o período necessário para a pré-secagem era de 1 semana e para a secagem de 48 horas. 


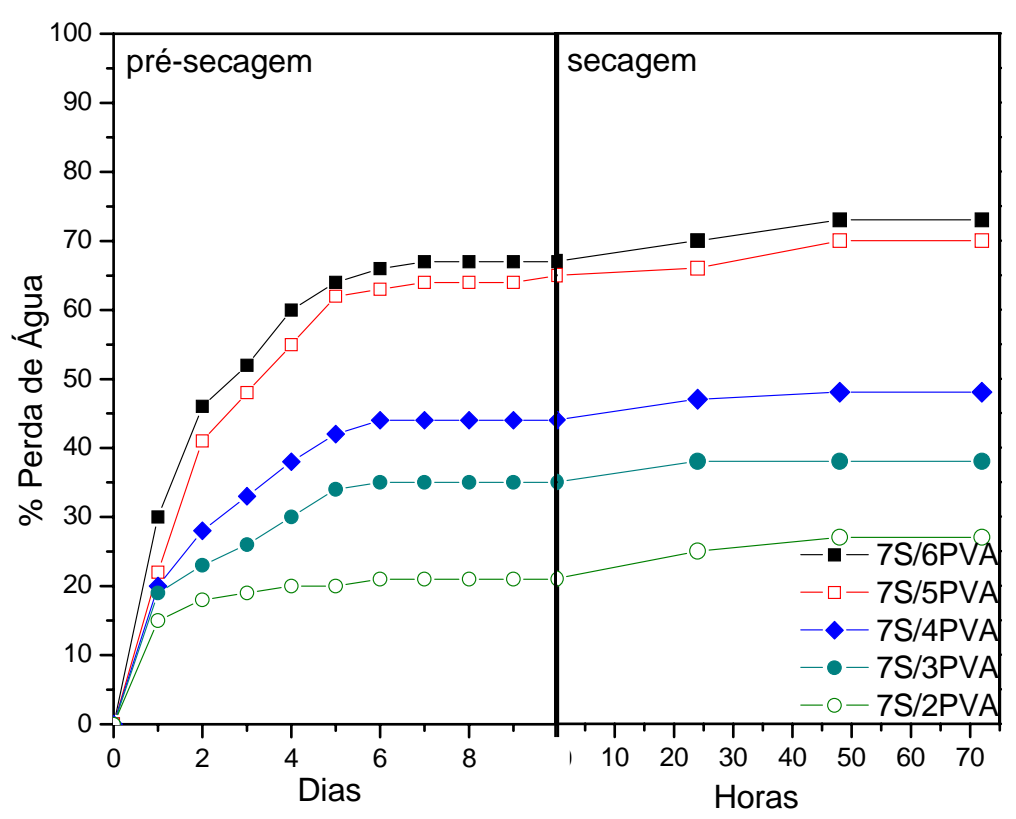

Figura 2: Porcentagem de perda de água das espumas híbridas durante os processos de pré-secagem e secagem pela rota 1.

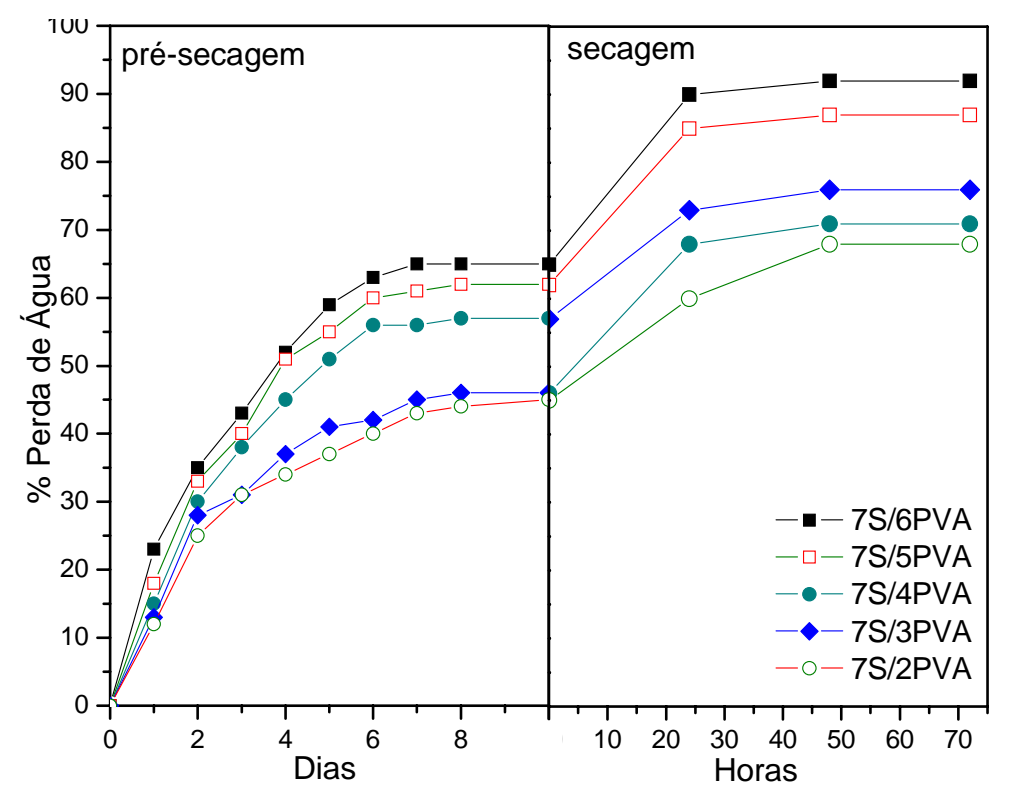

Figura 3: Porcentagem de perda de água das espumas híbridas durante os processos de pré-secagem e secagem pela rota 2.

Como conseqüência da menor contração sofrida, as espumas secas pela rota 2 apresentaram maiores diâmetros de poros (na faixa de 100 a $300 \mu \mathrm{m}$ ), além de estrutura de poros mais interconectados em comparação com as amostras secas pela rota 1, como mostrado na Figura 4. 

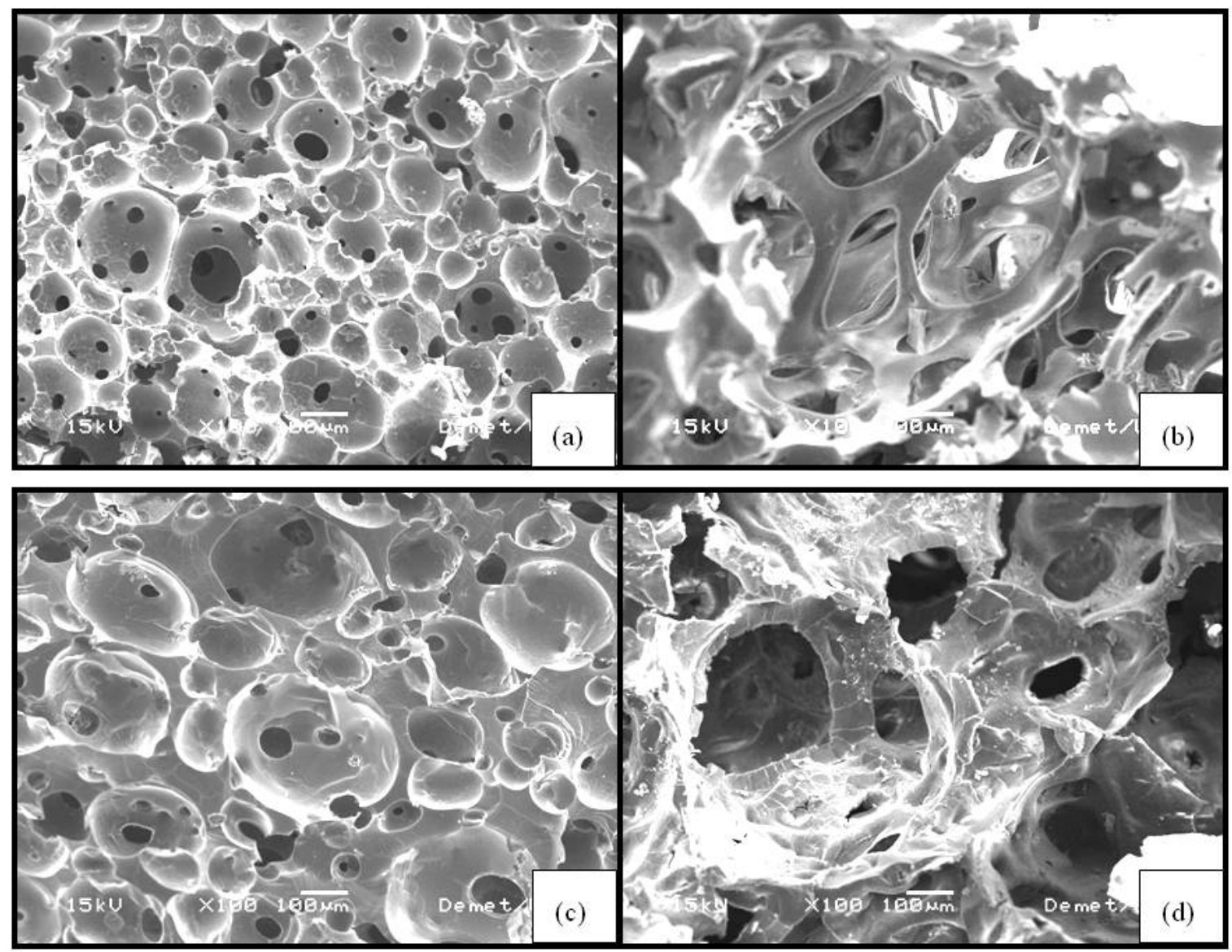

Figura 4: Micrografia de MEV, com aumento de 100x, das espumas híbridas com composição 7S/2PVA secas pelas rotas (a) 1 e (b) 2; e com composição 7S/6PVA secas pelas rotas (c) 1 e (d) 2.

A rota 2 foi então adotada como procedimento de secagem, sendo a etapa de pré-secagem a etapa final de produção da amostra, realizando-se a secagem completa apenas para caracterização das espumas. As porcentagens de contração sofridas pelas amostras durante as etapas de pré-secagem e secagem são mostradas na Tabela 3. As espumas não precisam estar completamente secas para serem usadas como matrizes para engenharia de tecidos, além disso, eliminando-se a etapa de secagem ganha-se tempo e evita-se maiores contrações das amostras (de 1,4 a 2,1\% a mais que na pré-secagem), contribuindo para se obter a porosidade final desejada.

Tabela 3: Porcentagens de contração da amostras nos estágios de secagem pela rota 2.

\begin{tabular}{llllll}
\hline Amostras & 7S/2PVA & 7S/3PVA & 7S/4PVA & 7S/5PVA & 7S/6PVA \\
\hline Pré-secagem & 28,0 & 30,5 & 31,9 & 32,8 & 34,0 \\
Secagem & 2,1 & 1,90 & 1,60 & 1,40 & 1,40 \\
Total & 30,1 & 32,4 & 33,5 & 34,2 & 35,4 \\
\hline
\end{tabular}

\subsection{Tamanho e Morfologia de Poros}

As espumas híbridas produzidas possuem tamanho de poros da ordem de 100-500 $\mu$ m e apresentam estrutura de poros interconectados, Figura 5, pode-se observar que a as espumas com maiores teores de PVA apresentavam menores tamanhos de poros. Observa-se também alteração da morfologia dos poros em amostras com diferentes teores de polímeros, Figura 6 . 


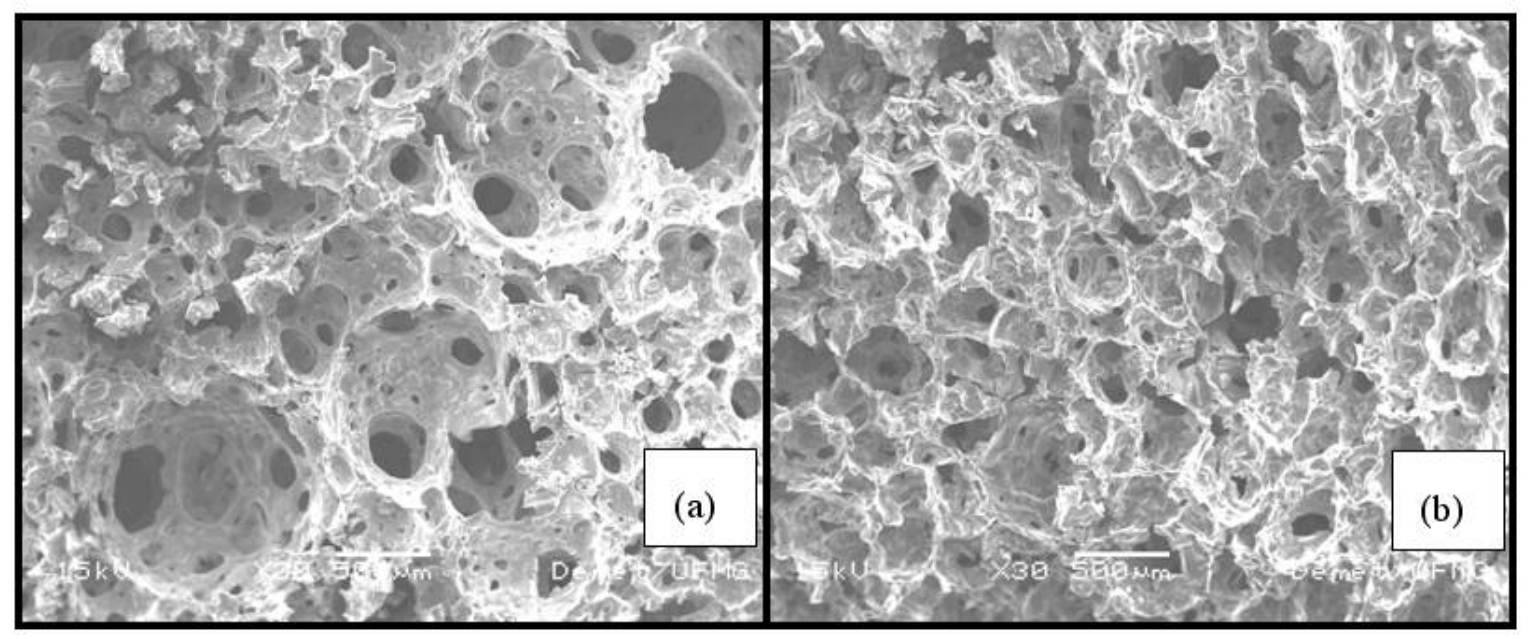

Figura 5: Micrografia de MEV, com aumento de 30x, da espuma híbrida com composição (a) 7S/2PVA, e (b) 7S/6PVA.

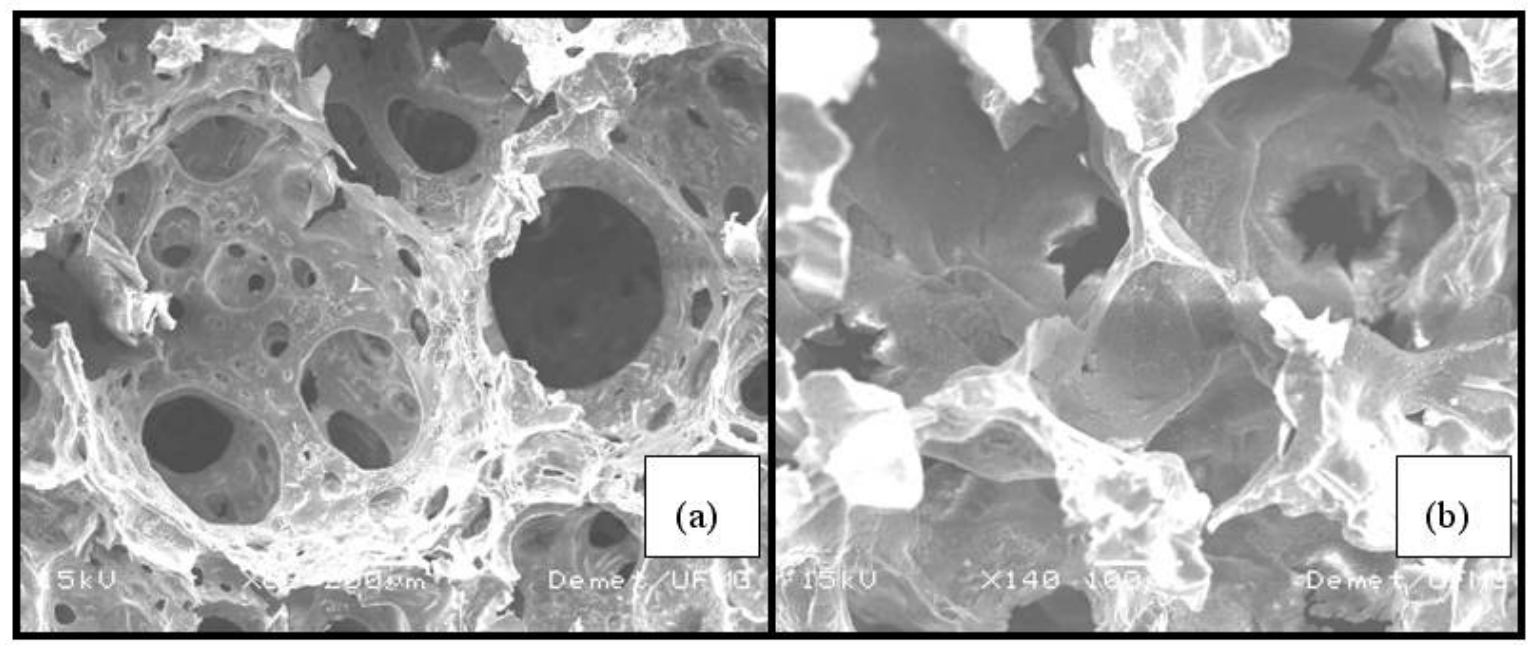

Figura 6: MEV da espuma híbrida com composição (a) 7S/2PVA, aumento de 100x; (b) 7S/6PVA, aumento de 140x.

\subsection{Propriedades Mecânicas}

As propriedades mecânicas das espumas híbridas produzidas foram avaliadas por ensaios de compressão em cp's obtidos na etapa de pré-secagem de preparação dos híbridos. As amostras foram obtidas nesse estágio porque para a aplicação em engenharia de tecidos não era necessária a produção de material totalmente seco. Além disso, pôde-se observar, qualitativamente, que as espumas secas apresentavam maior rigidez e fragilidade. A presença de água no material funciona como plastificante da rede polimérica, conferindo maior flexibilidade à estrutura dos híbridos.

Os ensaios foram realizados comprimindo-se os cp's até fim de curso dos limites estabelecidos. As curvas tensão x deformação obtidas das amostras produzidas nesse trabalho são apresentadas na Figura 7. Cp's contendo apenas fase inorgânica (7S) também foram submetidos à compressão com o objetivo de serem usados como referência. 


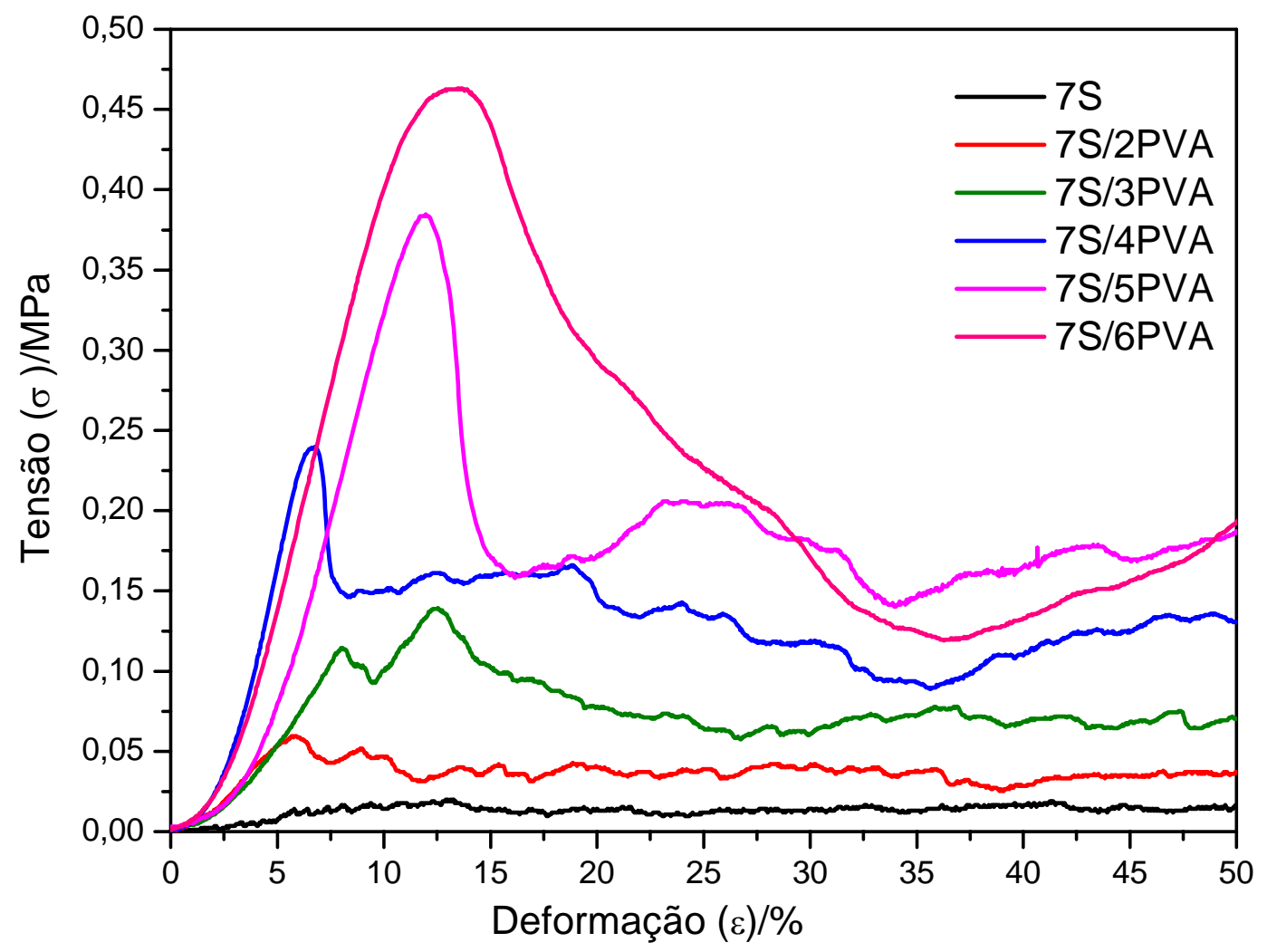

Figura 7: Curvas Tensão x Deformação das espumas híbridas de vidro bioativo/PVA com teores de polímero de 20 a $60 \%$.

As curvas obtidas demonstram que o material sofreu alteração de seu comportamento mecânico à medida que foi alterada sua composição. Pode-se observar pela curva correspondente ao vidro bioativo (7S) que este material apresenta um comportamento diferenciado quando comparado com aquele correspondente aos híbridos com teores mais elevados da fase orgânica, ocorrendo sucessivos acréscimos e diminuições nos valores de tensão, após a queda a partir do valor máximo. Uma interpretação dos eventos que ocorrem para a espuma de vidro está ilustrada na Figura 8 (a). A partir da tensão máxima de compressão, ocorre a ruptura da primeira linha de poros mais susceptíveis à fratura. Após essa ruptura, observa-se um aumento na tensão dado pelas linhas subseqüentes de poros ainda não fraturados. A tensão volta a diminuir novamente quando outras camadas de poros são rompidas. Essas fraturas ocorrem sucessivas vezes até que todo o material é fragmentado, sendo encontrado na forma de pó ao final do ensaio. Esse comportamento continuou sendo observado à medida que foram ensaiadas amostras contendo a fase polimérica, porém ficando cada vez menos intenso. À medida que se aumentava o teor de PVA dos híbridos, as curvas obtidas tinham comportamento mais parecido com o de materiais mais flexíveis. Isso se tornou mais evidente nos híbridos 7S/6PVA, onde a compressão da estrutura causou a deformação dos poros até o seu colapso, resultando em um material compactado ao final do ensaio, como esquematizado na Figura 8 (b).

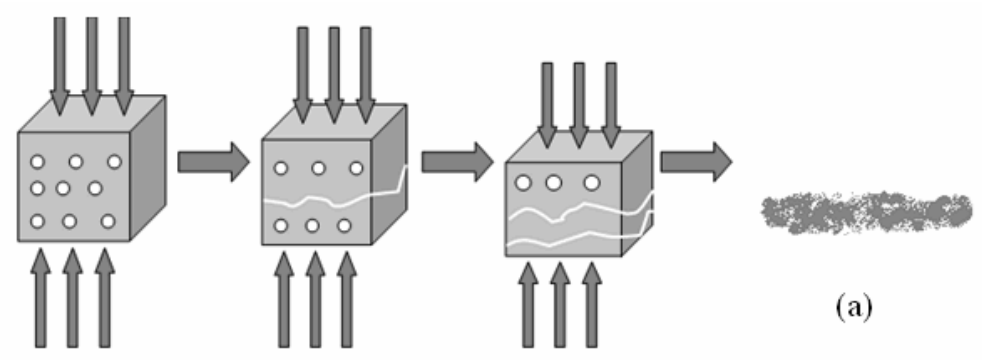




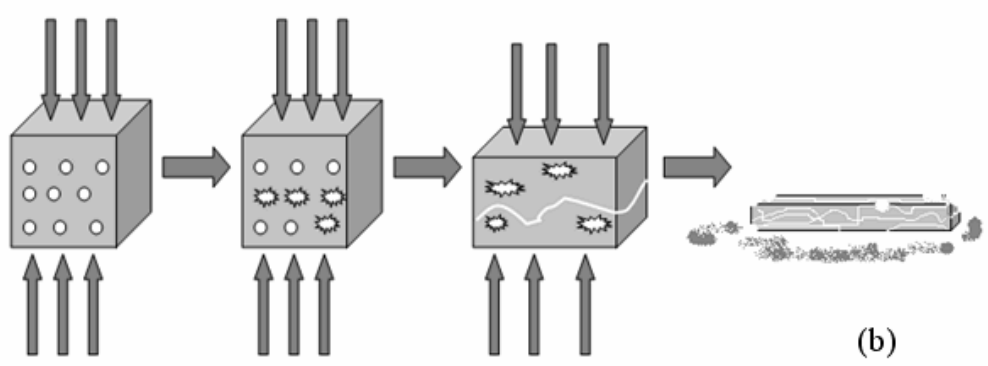

Figura 8: Esquema dos possíveis eventos ocorridos durante o ensaio de compressão em cp's de espumas 7S e 7S/6PVA.

As tensões correspondentes ao limite de resistência à compressão foram calculadas dividindo-se a força máxima de compressão pela área inicial da seção transversal do cp. As deformações máximas foram determinadas como sendo deformações correspondentes a uma tensão de $20 \%$ abaixo do valor da tensão máxima suportada pelo material. $\mathrm{O}$ módulo de elasticidade foi obtido pela inclinação da curva tensão $\mathrm{x}$ deformação no trecho elástico, de acordo com a Lei de Hooke. A tenacidade foi determinada como a área sob a curva até a deformação máxima. Os valores dos cálculos das propriedades mecânicas estão apresentados na Figura 9.

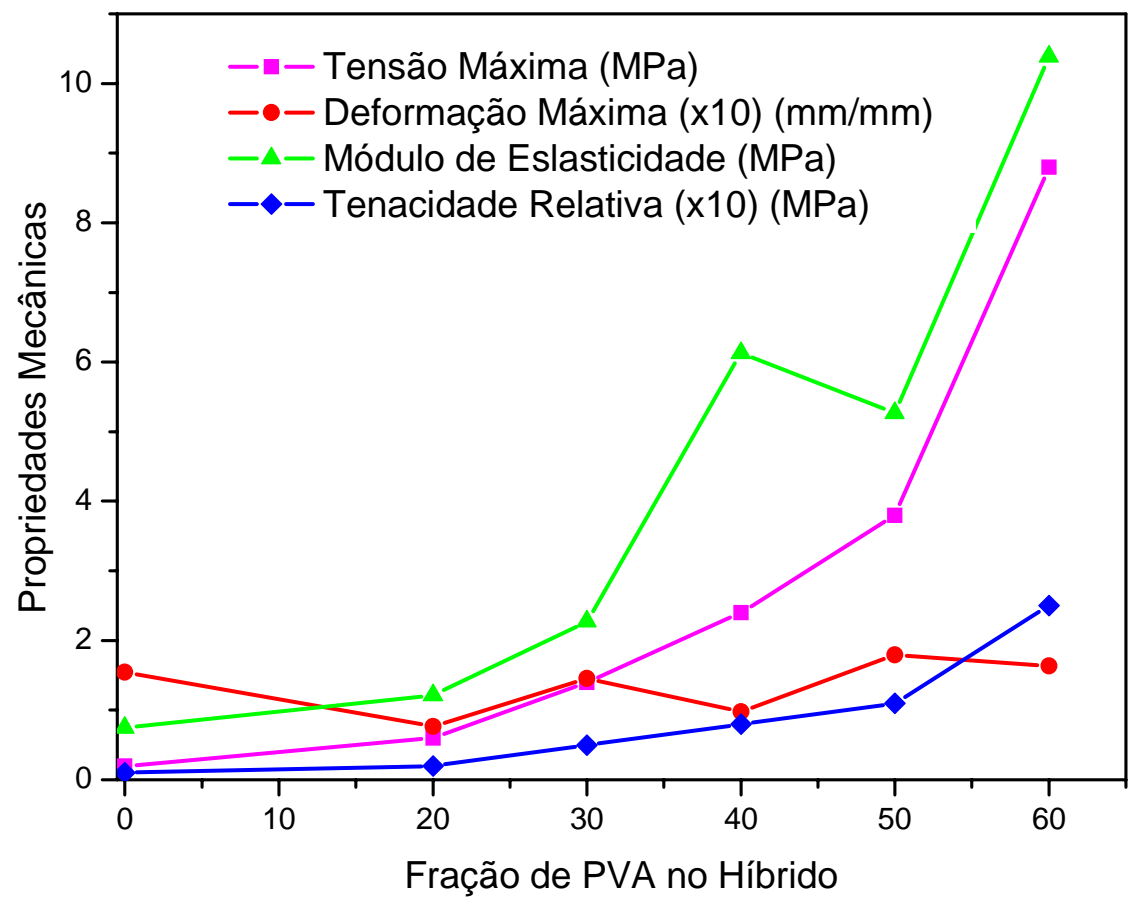

Figura 9: Resultados obtidos dos ensaios de compressão.

Os resultados obtidos mostram uma tendência de melhoria nas propriedades mecânicas das espumas à medida que se aumenta o seu teor de PVA. A tensão máxima suportada pelo material foi a propriedade que obteve maior variação, aumentando de 0,06 , amostras $7 \mathrm{~S} / 2 \mathrm{PVA}$, a $0,88 \mathrm{MPa}$, amostras $7 \mathrm{~S} / 6 \mathrm{PVA}$. A tenacidade relativa aumentou de $0,02(7 \mathrm{~S} / 2 \mathrm{PVA})$ para $0,25 \mathrm{MPa} /\left(\Delta \mathrm{l} / \mathrm{l}_{0}\right)(7 \mathrm{~S} / 6 \mathrm{PVA})$, esse aumento era esperado e está relacionado com a plasticidade do PVA.

Espumas híbridas desse sistema foram também obtidas por Pereira et al. $[10,11]$ para teores de polímeros de até $20 \%$. No presente trabalho, conseguiu-se o aumento do teor de PVA incorporado para $60 \%$. Uma comparação direta dos resultados de propriedades mecânicas obtidos nos dois trabalhos não é possível, uma vez que os ensaios foram feitos para tamanhos de cp's diferentes e a avaliação da porosidade das amostras do presente trabalho está em andamento. 


\section{CONCLUSÕES}

As espumas híbridas secas pela rota 2 apresentaram teores de perda de água na faixa de 68 a $92 \%$, sem que ocorressem grandes contrações dos seus diâmetros, entre 30 a $36 \%$. Possibilitando a produção de espumas com estrutura de poros pouco variável durante seu processamento, o que resulta em híbridos que atendem às condições de tamanho de poros (diâmetros na faixa de $100 \mu \mathrm{m}$ ) e interconectividade para aplicação em engenharia de tecidos. A rota 2 foi então adotada como procedimento padrão de secagem das espumas híbridas de vidro bioativo/PVA.

$\mathrm{O}$ aumento do teor de polímero na composição das espumas melhora consideravelmente suas propriedades mecânicas, como resistência à compressão e tenacidade, 98 e $96 \%$ maiores, respectivamente, em relação ao vidro bioativo (amostras 7S/6PVA). Contudo a estrutura de poros foi alterada, obtendo-se poros menores à medida que se aumentava o teor de PVA das espumas.

\section{BIBLIOGRAFIA}

[1] BRINKER, C.J., SCHERER, G.W., Sol-Gel Science: The physics and Chemistry of sol-gel Processing, Academic Press, Inc., London, pp. 908, 1990

[2] CALLISTER, W.D., Ciência e Engenharia de Materiais: Uma Introdução, ed. 5, LTC, Rio de Janeiro, 2002.

[3] CHIAVERINI, V., Tecnologia Mecânica, ed. 1, Mc Graw Hill, São Paulo, 1981.

[4] COELHO, M.B., "Desenvolvimento de metodologia para produção de matrizes tridimensionais porosas de vidro bioativo para aplicação em engenharia de tecidos", Tese D.Sc., DEMET/UFMG, Belo Horizonte, Brasil, 2003.

[5] HENCH, L.L., WILSON, J., An Introduction to Bioceramics. Advanced Series in Ceramic, v.1, World Science, Singapore, 1993.

[6] HENCH, L.L., POLAK, J.M., Third-generation Biomedical Materials, v. 295, Science, 2002.

[7] HOKUgO, A., TAKAMOTO, T., TABATA, Y., "Preparation of Hybrid Scaffold from Fibrin and Biodegradable Polymer Fiber”, Biomaterials, v. 27, pp. 61-67, 2006.

[8] LANGER, R., TIRRELL, D. A., “Designing Materials for Biology and Medicine”, Nature, v. 248, 2004.

[9] MATHIEU, L.M., et al., "Architecture and Properties of Anisotropic Polymer Composite Scaffolds for Bone Tissue Engineering", Biomaterials, v. 27, pp. 905-916, 2006.

[10] PEREIRA, M.M., et al., "Cytotoxicity Evaluation of Bioactive glass-polyvinil Alcohol Hybrid Foams Prepared by the sol-gel Method", Key Engineering Materials, v. 284-286, pp. 589-592, 2005.

[11] PEREIRA, M.M., JONES, J.R., HENCH, L.L., "Bioactive Glass and Hybrid Scaffolds Prepared by solgel Method for Bone Tissue Engineering “, Advances in Applied Ceramics, v. 35, pp. 104, 2005.

[12] SALINAS, A. J. et al., "Bioactive organic-inorganic Hybrids Based on CaO-SiO2 sol-gel Glasses", Key Engineering Materials, v. 254-256, pp. 481-484, 2004.

[13] VASCONCELOS, V.L., PEREIRA, A.P.V., ORÉFICE, R.L., "Novos Biomateriais: Híbridos Orgânicoinorgânicos Bioativos", Polímeros, v. 9, n. 4, pp. 104-109, 1999.

[14] WARNKE, P.H., et al., "The Mechanical Integrity of in vivo Engineered Heterotopic Bone", Biomaterials, v. 27, pp. 1081-1087, 2006. 